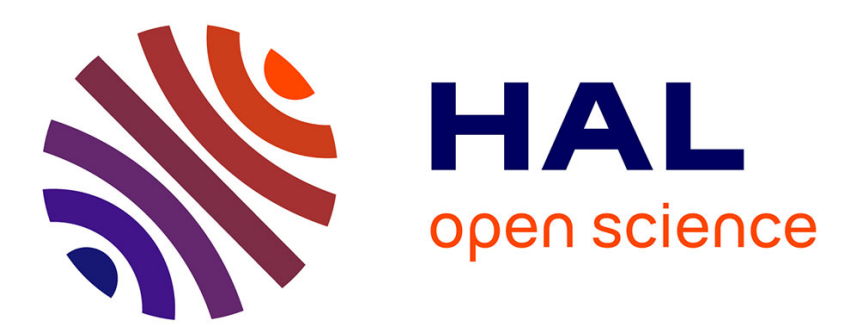

\title{
The Role of R\&D Collaboration Networks on Regional Innovation Performance
}

\author{
Cilem Selin Hazir, James Lesage, Corinne Autant-Bernard
}

\section{To cite this version:}

Cilem Selin Hazir, James Lesage, Corinne Autant-Bernard. The Role of R\&D Collaboration Networks on Regional Innovation Performance. 2014. halshs-01073031

\section{HAL Id: halshs-01073031 \\ https://shs.hal.science/halshs-01073031}

Preprint submitted on 8 Oct 2014

HAL is a multi-disciplinary open access archive for the deposit and dissemination of scientific research documents, whether they are published or not. The documents may come from teaching and research institutions in France or abroad, or from public or private research centers.
L'archive ouverte pluridisciplinaire HAL, est destinée au dépôt et à la diffusion de documents scientifiques de niveau recherche, publiés ou non, émanant des établissements d'enseignement et de recherche français ou étrangers, des laboratoires publics ou privés. 
The Role of R\&D Collaboration Networks on Regional Innovation Performance

Cilem Selin Hazir, James LeSage, Corinne Autant-Bernard

October 2014 


\section{GATE Groupe d'Analyse et de Théorie Économique Lyon-St Étienne}

93, chemin des Mouilles 69130 Ecully - France

Tel. +33 (0)4 72866060

Fax $+33(0) 472866090$

6, rue Basse des Rives 42023 Saint-Etienne cedex 02 - France

Tel. +33(0)4 77421960

Fax. +33 (0)4 77421950

Messagerie électronique / Email : gate@gate.cnrs.fr

Téléchargement / Download : http://www.gate.cnrs.fr - Publications / Working Papers 


\title{
The Role of R\&D Collaboration Networks on Regional Innovation Performance
}

\author{
Cilem Selin Hazır ${ }^{* 1}$, James LeSage ${ }^{\dagger 2}$, and Corinne Autant-Bernard ${ }^{\ddagger 1}$ \\ ${ }^{1}$ Université de Lyon, Lyon, F-69007, France; CNRS, GATE Lyon Saint-Etienne, Ecully, \\ F-69130, France; Université Jean Monnet, Saint-Etienne, F-42000, France. \\ ${ }^{2}$ Fields Endowed Chair in Urban and Regional Economics, McCoy College of Business \\ Administration, Texas State University, San Marcos, Texas 78666.
}

October 8, 2014

\begin{abstract}
In this study, we consider $\mathrm{R} \& \mathrm{D}$ collaboration networks as a mechanism that modifies knowledge flows in space, and hence as another source of interaction among regional innovation processes. Our objective is to understand the relative role of spatial neighbors and network neighbors on patenting performance of regions. We make use of data on R\&D collaborations supported by the European Union's Framework Programs (FP) and empirically investigate the patent activity of 213 European regions in the field of ICT during 2003-2009. Concerning the short length of the time frame we adopt a static modeling strategy and specify a spatial Durbin Model. As spatial neighbors intersect with network neighbors we decompose neighbor regions into three sets: spatially proximate regions that are not collaboration partners, spatially proximate regions that are collaboration partners, and distant collaboration partners. We express the weight matrix as a convex combination of these three sets and by means of gridding we compare how model fit changes as we move from a purely space based view to a purely network based view to express the dependence structure. The weight matrix that performs the best accords $60 \%$ weight to distant collaboration partners, $30 \%$ weight to proximate collaboration partners and $10 \%$ weight to proximate regions with whom there is no FP collaboration. This result reveals that the interaction (proximate and distant) among European regions within FP networks in the field of ICT is key for understanding dependence among their patenting performances.
\end{abstract}

\footnotetext{
*cilemselin@gmail.com

†james.lesage@txstate.edu

¥ corinne.autant@univ-st-etienne.fr
} 
Keywords: R\&D collaboration networks, innovation performance, spatial econometrics, ICT

JEL Classification: C21, L14, O31, O52, R12, R15.

\section{Introduction}

External knowledge is considered to be a key input for innovation activities that take place both at the organizational and regional level (Chesbrough, 2003: Hagedoorn and Wang, 2012; Cassiman and Veugelers, 2006; Jensen et al., 2007). As a matter of fact, knowledge is not evenly distributed across regions, and hence knowledge flows are important for regions to fuel their economy with new products, processes, new ways of organizing work and new ways of marketing. It is also important from an economic convergence perspective concerning the theoretical findings suggesting that cross-regional knowledge flows leads to reducing uneven growth (Baldwin and Forslid, 2000; Baldwin et al., 2001).

Concerning the role of external knowledge, R\&D collaboration networks, which keep growing and getting more complex (Roediger-Schluga and Barber, 2006; Hagedoorn, 2002, Wuchty et al., 2007), loom large as they provide the network members with the potential to benefit from knowledge produced elsewhere. Especially, project-based collaborations serve as flexible tools as participants preferentially create synergies in $R \& D$ towards a concrete research goal and within a schedule. As compared to other mechanisms that enable knowledge to flow, like buzz, imitation, patent documents, scientific articles, or trade of goods and services, these interactions allow not only exchanging existing knowledge but also creating new knowledge collectively. Also, in the case of project based R\&D collaborations intentional interactions underly knowledge flows more substantively. However, the social medium created by these interactions could possibly favor unintentional knowledge flows (spillovers) by means of observing, imitating, or buzz.

At the European level development of R\&D collaboration networks constitutes a key element of the innovation policy mix. Funding of Framework Programs transnational research projects in various fields has a goal of promoting collaboration networks that will promote economic growth and competitiveness through $\mathrm{R} \& \mathrm{D}$ and innovation. The design of the support program is such that project consortiums must include international partners in an effort to reinforce European wide knowledge flows and enable innovation actors to couple local knowledge flows with global flows to nurture innovation.

The objective of this study is to consider R\&D collaboration networks as a source of interaction among regional innovation processes and investigate how network mediated flows affect innovation performance alongside more traditional spatial interaction between proximate neighbors. The answer to 
this question might deepen our understanding in two ways. First, since public funds are used to promote formation of R\&D networks, it would be useful to quantify the magnitude and significance of regional participation in R\&D collaboration networks on regional innovation performance. Second, R\&D collaboration networks enable both spatially proximate and/or distant partners to become direct learning partners. Identifying the relative role played by distant and proximate direct learning partners on regional innovation performances is key to understand the relative impact of space and collaborations on innovation. Such an understanding has policy implications, since it will help evaluate the impact of programs such as public support for distant collaboration with respect to more spontaneous (and potentially unbalanced) development processes that arise due to spatial proximity.

Early applied econometric literature produced numerous efforts to quantify the effect of knowledge flows on regional innovation performance Anselin et al., 1997; Autant-Bernard, 2001; Bottazzi and Peri, 2003; Moreno et al., 2005: Greunz, 2003 Peri, 2005). In these studies, local knowledge externalities were considered the source of interaction among regional innovation processes. Thus, spatial proximity has been used to define the neighbors that supply a region with external knowledge. More recently, several studies have also taken network-mediated knowledge flows and their impact on innovation performance into account (Maggioni et al., 2007; Boschma and Wal, 2007; Ponds et al., 2010; Broekel, 2012; Sebestyen and Varga, 2013). This literature developed along two main perspectives. The first one aims at quantifying the respective role played by different types of proximity. It makes use of spatial and/or social weight matrices to compare social and spatial effects (Maggioni et al., 2007; Ponds et al., 2010). However, since social linkages often take place locally, these approaches fail to disentangle spatial effect from social effects. The second research perspective builds upon recent theoretical advances regarding knowledge diffusion processes through collaboration networks. While the positive impact of local ties has been clearly pointed out (Almeida and Kogut, 1999), the virtue of global ties is widely acknowledged as well (Guiliani and Bell, 2005; Boschma, 2005). Local ties benefit from proximity effects which reduce transaction costs and favor repeated interactions. However two much inward orientation may reduce creativity. Conversely, global ties could ensure access to more updated and complementary knowledge. Distant ties are even considered a key to preventing territorial lock-in. The literature on industrial clusters emphasizes that leading actors in regional innovation may act as knowledge gatekeepers who facilitate entry of external knowledge (Guiliani and Bell, 2005). But an excess of external exposure may turn into technological dependence and lack of autonomous innovation. In this respect, small worlds, combining a dense set of local ties and a few distant ties have been identified as the most efficient network structure (Cowan and Jonard, 2004, Kastelle and Steen, 2010). According to Kastelle and Steen (2010), small worlds improve the efficiency 
of linking together heterogeneous communities of actors who posses diverse mental models, routines and cognitive maps From an empirical perspective, several studies show that most links are established within geographical areas (Almeida and Kogut, 1999 ; Singh, 2005) involving, in turn, a higher level of local knowledge diffusion (Breschi and Lissoni, 2009). However, little attention has been devoted to the impact of knowledge mediated by global pipelines. The proper impact of the geographical scope of network collaboration on innovation performance remains therefore poorly assessed so far. In some studies, the focus is on collaboration or network structure within an area and ties linking inventors located in one area with inventors located in different areas are disregarded. This approach exhibits the positive role played by dense networks within an area. Conversely, other studies focus on remote collaboration only. Beaudry and Schiffauerova (2011) point out for instance that distant collaborations positively impact patent quality. Quite a few studies analyze both local and distant ties. In the specific case of the Canadian biotech industry, Gertler and Levitte (2005) highlight their complementary role on innovation success. Bell and Zaheer (2007), relying on a sample of Canadian firms as well, find that geography significantly influences the extent to which ties at different levels of analysis (individual, organization or institutional ties) act as conduits of knowledge. To our knowledge, there is only one attempt to run wider-scale investigations at a territorial level.Using patent data, Breschi and Lenzi (2014) explore the impact of network spatial structure on US cities innovation. Their results confirm the complementarity between local and global. Focusing on collaborations, these studies neglect however less intentional knowledge flows, making it impossible to disentangle collaboration based knowledge flows from other types of spatial dependence.

In contrast to these studies, we decompose neighbor regions into three sets: spatially proximate regions that are not collaboration partners, spatially proximate regions that are collaboration partners, and distant collaboration partners. Hence, we investigate marginal and joint effects of spatial distance and collaborations on regional innovation performance. We thus contribute to the literature on knowledge diffusion in two ways: 1) we provide empirical evidence on the role of physical distance versus social distance and, 2) we assess the impact of local collaborations versus distant collaborations on regional innovative performance.

In our empirical application we study the patent activity of 213 European regions in the field of ICT during 2003-2009. We make use of data on R\&D collaborations supported by the European Union's Framework Programs (FP) to represent the inter-regional network. Since the data spans a short period, we use a static modeling strategy and use a spatial Durbin model specification 1 Our findings, suggest patent activity of European regions

\footnotetext{
${ }^{1}$ Lesage and Pace (2009) as well as Elhorst (2010) argue this particular specification
} 
in the field of ICT are fostered mainly by knowledge flows from distant collaboration partners in FP. Moreover, a substantial part of local knowledge flows stem from spatial neighbors that are also collaboration partners.

In section 2, we first discuss mechanisms of knowledge flows and relate these to the definition of a connectivity structure needed for empirical work. Section 3 sets forth the model and explains the empirical implementation. We present the empirical findings and interpret them in section 4. A final section summarizes our conclusions and discusses possible future research directions.

\section{Knowledge Flows and Dependence among Re- gional Innovation Processes}

\subsection{Sources of Dependence}

Knowledge, which is key for innovation may flow among innovation actors in a number of ways and act as a source of dependence among regional innovation processes. First, flows that occur through buying and selling of goods allow the receiver to learn by using the good and perhaps trying to discover knowledge it embodies through reverse engineering. Hence, at least some part of the knowledge (tacit or codified) that is assembled together through the production of the good is non-excludable. An influential study by Coe and Helpman (1995) weights trading partners' knowledge stocks using import shares, showing that countries who import more from high R\&D countries have higher total factor productivity. Keller (1998) challenged this finding by demonstrating that use of random weights instead of import shares yields evidence of larger international knowledge spillovers. However, in a more recent study he concludes that knowledge flows between some countries occur primarily via trade, while in other countries these flows arise from other channels (Acharya and Keller, 2009).

Knowledge flows can also arise because of labor market mobility. Personnel turnover stirs knowledge among innovation actors as organizations learn through individuals by integrating the individual's knowledge into the organization. Professional mobility not only enables flows of tacit knowledge that is embedded in people's minds and habits, but also changes the ability to access tacit or codified knowledge, because each professional is embedded in a social network. Almeida and Kogut (1999) trace mobility of inventors using patent data and show that the receiving organization cites the former patents of the new employee more than those of other firms. They also show that knowledge flows via labor markets tend to be localized since space constrains the mobility of individuals. Several other studies corroborate these findings (Zucker et al., 1994, Balconi et al., 2004).

has numerous advantages in applied work. 
Yet another way flows can occur is through patent documents, scientific articles, technical reports, specialized magazines, etc. These materials codify at least some part of the scientific, technical or market knowledge. Nevertheless, the amount of codified knowledge varies with respect to the novelty of the topic or market. Knowledge on well-established topics/markets is less tacit as compared to frontier research fields and new markets (Saviotti, 1998). In their seminal work, Jaffe et al. (1993) investigate the spatial extent of knowledge flows that occur through patent documents and show that flows through citations are more likely to occur when the innovators are co-located. However, more recently it has been argued that social proximity is what facilitates these flows, with the marginal contribution from geographical proximity being low (Agrawal et al., 2008, Singh, 2005).

Knowledge also flows through non-deliberate face-to-face or electronic interaction. Asheim et al. (2007) label these types of flows buzz, and define buzzing activities as group-based self-generating exchange of information and knowledge outside formal collaboration. They argue that buzzing enables transmission of 'special know-how' types of knowledge, and that transmitting such tacit knowledge plays a key role in industries that heavily rely on individual talent, skills, and creativity. They also suggest that in different industries, depending on the underlying knowledge base, the spatial extent of buzzing activities might vary.

Last but not the least, deliberate interactions lead to knowledge flows as well. Deliberate interactions refer to the case where the objectives, scope, and horizon of interaction is specified through formal agreements and the rights of interacting parties are secured. Joint ventures, project-based R\&D collaborations are of this type. Deliberate interactions result in both exchange of different pieces of knowledge, co-creation of new knowledge, and allows transmission of both tacit and codified knowledge. As these interactions lead to creation of a relational space, where social interaction takes place and individuals can observe each other, apart from intentional flows they may give rise to spillovers as well.

There is little doubt that spatial proximity favors several of the channels of knowledge diffusion described above. In spite of trade globalization, buying and selling goods is still significantly influenced by physical distance as shown by the gravity models (Anderson and van Wincoop, 2004). Similarly, labor mobility and face-to-face contacts are mainly local processes (Breschi and Lissoni, 2009). It is therefore relevant to use spatial proximity to express the dependence structure. However distant knowledge flows occur as well. As for deliberate interactions, it has especially been pointed out that the shape of geographical linkages is becoming more and more global. Empirical evidence on knowledge flows through deliberate interactions has relied on a wide range of indicators like co-inventions, co-publications, and joint R\&D projects. Hoekman et al. (2010) focus on European co-publication networks, and suggest that although physical distance dampens co-publication 
intensity, its effect is decreasing over time. Ter-Wal (2013) investigates coinvention networks in Germany in the field of biotechnology. He concludes that, at the early stages of the industry, deliberate interactions are much more constrained by geographical proximity but over time this becomes less important. For the case of $R \& D$ project collaborations empirical evidence is mixed. Autant-Bernard et al. (2007a) report that physical distance has no effect on collaboration choices for micro and nanotechnologies field. Conversely, Paier and Scherngell (2008) report a negative role played by physical distance but they state that there are more important determinants of partner choice like joint history or similarity in knowledge bases. Scherngell and Lata (2013) conclude that country border effects are decreasing over time. Hazır and Autant-Bernard (2014) investigate cross-regional collaborations in the field of biotechnology and suggest that regions tend to collaborate with geographically proximate regions, but these connections do not cluster locally in a strict way as geographically proximate regions are involved in a closure process that links both to a distant region.

These findings suggest that some mechanisms are strongly affected by spatial distance and they facilitate knowledge flows more from geographically proximate regions and less from distant regions. This motivates using spatial proximity to express the structure of dependence among regional innovation processes. However, research on the spatial dimension of networks suggest that network mediated flows may occur both from geographically proximate and distant regions. This implies two conclusions. First, spatial contiguity or spatial distance alone may not reflect the nature of dependence among innovation processes taking place in different regions, since regions' direct learning partners are not always those that are spatially proximate. Second, in order to understand the effect of network mediated knowledge flows, one needs to disentangle spatial and network interactions among regions.

\section{$2.2 \quad$ Structure of Dependence}

Let $S=\left\{s_{1}, s_{2}, \ldots, s_{N}\right\}$ be the set of regions and $W_{N \times N}$ ( $W$ from now on) be the weight matrix indicating the structure of interaction among regional innovation processes, in other words, learning partners. We express $W$ as a convex combination of three mutually exclusive components: $W_{1}, W_{2}$, $W_{3}$. Among these, $W_{1}$ indicates strength of interaction among spatially proximate region pairs that are not collaborating. $W_{2}$ indicates strength of interaction among spatially proximate region pairs that are collaborating; whereas, $W_{3}$ shows strength of interaction among distant region pairs that are collaborating. Letting $\lambda_{1}, \lambda_{2}$, and $\lambda_{3}$ be the corresponding weights for $W_{1}, W_{2}, W_{3}$, respectively, $W$ can be expressed as follows: 


$$
\begin{aligned}
W= & \lambda_{1} * W_{1}+\lambda_{2} * W_{2}+\lambda_{3} * W_{3} \\
& \lambda_{1}+\lambda_{2}+\lambda_{3}=1
\end{aligned}
$$

Such a definition of $W$ serves the research objectives of this study discussed in section 1. First, it allows us to specify network-mediated flows in the presence of local knowledge flows and compare different mechanisms through which spatial advantages work on innovation processes. This is done by accommodating both of these types of connectivity through the matrices $W_{1}$ and $W_{2}$ and scalar parameters $\lambda_{1}, \lambda_{2}$ associated with these. Second, the specification allows for both local and distant collaboration partners by including weight matrices $W_{2}$ and $W_{3}$, with associated parameters $\lambda_{2}, \lambda_{3}$. Estimated magnitudes for the scalar parameters $\lambda_{1}, \lambda_{2}, \lambda_{3}$ that assign weights to the different types of connectivity can be used to draw inferences that are informative about: the design of network policies; and the role played by different types of regional collaboration networks on regional innovation.

\section{The Model}

Using the definition of $W$ introduced in the previous section, we work on a spatially extended Knowledge Production Function (KPF) framework. The KPF framework first proposed by Griliches (1979), leaves detailed events taking place during the innovation process aside, and provides an overall assessment by linking own and external innovation inputs to innovation outputs. KPF is assumed to have a Cobb-Douglass form and a baseline specification can be expressed as follows:

$$
\text { Inn }_{i}=\alpha\left(\text { Characteristics }_{i}\right)^{\beta 1}\left(\text { OwnResearch }_{i}\right)^{\beta 2}\left(\text { ExternResearch }_{i}\right)^{\beta 3}
$$

Autant-Bernard and LeSage (2011) use theoretical reasoning related to the fact that external effects of research might raise from both observable and unobservable inputs. They show that this results in a spatial regression extension to KPF taking the form of a spatial Durbin model (SDM) specification. Using this result, we work with the following model, which is in log-linear form:

$$
\mathbf{y}_{\mathbf{t}}=\lambda \mathbf{W} \mathbf{y}_{\mathbf{t}}+\mathbf{X}_{\mathbf{t}} \boldsymbol{\beta}+\mathbf{W} \mathbf{X}_{\mathbf{t}} \boldsymbol{\delta}+\mathbf{c}+\alpha_{t} \mathbf{l}+\mathbf{v}_{\mathbf{t}}
$$


$y_{t} \quad$ is a column vector of size $n \times 1$ with entries showing the innovation output in region $i \in S$ at time $t \in \tau$.

$W$ is an $N \times N$ weight matrix as defined in (1). In (1), $W_{1}, W_{2}$, and $W_{3}$ are all row-normalized, hence $W$ also has row sums of unity.

$\lambda \quad$ is the parameter showing the strength of dependence among regions' innovation outputs.

$X_{t}$ is a $n \times k$ matrix of individually and time varying nonstochastic regressors representing regional inputs to innovation.

$\beta \quad$ is a $k \times 1$ vector of coefficients associated with $k$ innovation inputs in $X_{t}$.

$\delta \quad$ is the parameter showing the strength of dependence among regions' innovation inputs.

$c \quad$ is an $n \times 1$ column vector of individual effects.

$\alpha_{t}$ is the $t^{t h}$ element of the $m \times 1$ column vector of fixed time effects.

$l \quad$ is a $n \times 1$ column vector of ones.

$v_{t} \quad$ is an $n \times 1$ column vector of identically and independently distributed error terms with zero mean and variance $\sigma_{0}^{2}$.

The model allows us to study the effects of intra-temporal knowledge flows that occur locally (in the presence or absence of collaboration) or globally (via collaboration). In other words, the model enables quantifying the static effects of knowledge; i.e. the effects of the current knowledge on the current innovative activities. However, knowledge might have also dynamic effects (Glaeser et al., 1992; Henderson, 1997), which stem from the cumulative property of knowledge and refer to the effects of prior accumulated knowledge on the current innovation activities. Despite this, we do not work on a dynamic model because dynamic effects occur with a lag and the temporal scope of our data set is not large enough to observe and quantify lagged effects properly.

\section{Empirical Application: Patenting performance of European regions in ICT}

As an empirical application, the model presented in the previous section is implemented to quantify the effect of knowledge flows on patent activity of European regions in the field of Information and Communication Technologies (ICT). As a matter of fact, patents as indicators of innovation performance have some limitations (Griliches, 1990; Kleinknecht et al., 2002). Patents signify an invention but inventions are not equivalent to innovations. One of the reasons is that not all innovations are preceded by inventions. 
Moreover, even if they start with an invention phase, the scope of innovation activities is broader since they include further steps that are essential for transforming inventions into new goods, services, processes, etc. In addition, all inventions do not necessarily end up as successful innovations, since some attempts at innovation are abandoned after the invention phase. Furthermore, all inventions are not filed as patent applications, meaning that patent data reflects only registered inventive activities that might or might not be associated with innovations. Despite these well-known limitations, patents are used as a proxy for innovative activity in this study due to the availability of patent data at the regional level.

The focus on a single knowledge field is based on the rationale that in different fields the role of mechanisms described in subsection 2.1 may differ, and hence the relative role played by geographically proximate and distant regions as sources of external knowledge may differ. There are two motivations for our focus on ICT. First, ICT is a horizontal field as developments in ICT have impacts on a number of other fields. ICT innovations trigger not only product innovations in other fields but also lead to restructuring of the production processes, and changes in the organizational forms or marketing methods. Second, ICT sample data regarding the FP was more developed, providing us with better measures of R\&D collaboration in this field.

\subsection{Variables and Data}

Concerning availability of external data at the regional level, the study covers regions located in 26 countries (EU-27 members except Bulgaria and Greece, and Norway). Regions are defined by means of a modified NUTS-2 classification. Some NUTS-2 regions, which are islands far from the mainland, are excluded. For Belgium, Denmark and United Kingdom some NUTS-2 regions are replaced with their NUTS-1 counterparts. The rationale behind this replacement is that in NUTS classification the use of population as a criterion results in large variation in the spatial dimension of NUTS-2 regions. In Belgium, Denmark and United Kingdom NUTS-2 regions are so small that they can hardly be compared with their counterparts in other EU countries. To illustrate, in the United Kingdom, London city belongs to several NUTS-2 regions. Thus, based on earlier work by EuroLIO 213 regions are covered in the empirical analysis.

By making use of several data sources we prepared a panel data set for these 213 regions and for 7 years. The time window for the dependent variable and the explanatory variables are not the same due to the fact that research inputs are not immediately converted to inventions and filing an invention in a patent office takes time. In this research we assumed a lag of three years. Thus, the time window for the dependent variable spans

\footnotetext{
${ }^{2}$ European Localized Innovation Observatory (http://www.eurolio.eu/)
} 
2003-2009; whereas, for the explanatory variables it spans 2000-2006.

The dependent variable which we label Patents represents the number of patents in a region at a point in time, measured by the number of patent applications to the European Patent Office (EPO)(localized with respect to the inventor(s)'s country of residence) in the field of ICT. Data on regional patents is obtained from OECD Regpat Database (June 2012).

Explanatory variables consist of three main inputs to innovation. The first, $B E R D$ refers to financial inputs to research. It is defined as the amount of regional R\&D expenditures (in million PPS) in the field of ICT performed by the business enterprise sector (Source: Eurostat). Nevertheless data on sectoral breakdown of regional $\mathrm{R} \& \mathrm{D}$ expenditures is not available. Hence, an approximation is made for each region by multiplying the total regional R\&D expenditures performed by the business enterprise sector (in million PPS) by the ratio of ICT publications to all publications in all domains. The second explanatory variable $H R S T$ measures human resources as another input to the innovation process. It is defined as the number of people either having successfully completed education at the third level in an SET field of study; or, although not formally qualified as in the first case, employed in an SET occupation where qualifications in the first case are normally required (Source: Eurostat). The third explanatory variable, Specialization refers to the extent that knowledge generating activities in a region are focused in ICT. Regions that are more focused in ICT are more specialized and due to their expertise they perform better in transforming innovation inputs to inventions. Specialization is expressed as an RTA index by EuroLIO 3 , which extracted the data originally from the PASCAL (INIST-CNRS) ${ }^{4}$ database. This index is obtained by taking the ratio of two shares: the share of ICT publications of a region in its overall portfolio of publications, and the share of ICT publications in total number of publications for all regions. When the index is greater than one the region is more specialized in ICT as compared to the average.

\subsection{Construction of Weight Matrices}

As explained in section 2.2, we express $W$ as the weighted sum of three weight matrices $W 1, W 2, W 3$. To build these matrices we first determine regions that are spatially proximate, and select 12 nearest neighbors using distance between centroids. Next, an R\&D collaboration network among regions was constructed. We note that $\mathrm{R} \& \mathrm{D}$ collaboration networks are dynamic since the set of collaboration partners for regions changes over the seven year time period for which we have data. In addition to changing collaboration partners, the strength of interaction between regions based on

\footnotetext{
${ }^{3}$ European Localized Innovation Observatory (http://www.eurolio.eu/)

${ }^{4}$ Institut de l'Information Scientifique et Technique - Centre National de la Recherche Scientifique (http://www.inist.fr/)
} 
collaboration links can also change. Since our empirical model is static, we made use of a collaboration network constructed for a single year 5

To build the collaboration connectivity structure, we made use of European Commission records on transnational collaboration ICT projects that received a grant through the Framework Programs (FP) in 2000. An advantage of using FP data is that this data source is more comprehensive than other methods that have been used such as co-invention or co-publication networks. The FP covers collaborative research activity of all types of organizations; i.e. universities, private enterprises, public research bodies, non-profit organizations.

The connectivity structure was based on a valued inter-organizational $\mathrm{R} \& \mathrm{D}$ collaboration network, in which network ties are based on the number of running projects that any two organizations had in common in 2000 . Groups of organizations belonging to the same region were identified and the strength of collaboration assigned to regions $(i$ and $j, i \neq j$ ) was obtained by summing the values of ties that connect groups of organizations in region $i$ to group of organizations in region $j$.

\subsection{Estimation and Results}

First, by means of gridding we compare how model fit changes as we move from a purely proximity-based view to a purely collaboration network-based expression for the dependence structure. We start with the case where $\lambda_{1}=1$, and $\lambda_{2}=\lambda_{3}=0$ and evaluate the log-likelihood for the model presented in (3). In other words we estimate the model where dependence among regional innovation processes is assumed to have a purely spatial structure. Then, we use a step size of 0.1 , increment $\lambda_{2}$ and $\lambda_{3}$ use the following looping procedure to evaluate the log-likelihood for each case (there are 66 possible combinations):

$$
\begin{aligned}
& \text { while } \lambda_{1} \geq 0 \text { : } \\
& \qquad \begin{array}{l}
\text { set } \lambda_{3}=1-\lambda_{1} \\
\text { while } \lambda_{3} \geq 0 \text { : } \\
\quad \text { set } \lambda_{2}=1-\lambda_{1}-\lambda_{3} \\
\quad \text { evaluate the likelihood } \\
\quad \text { set } \lambda_{3}=\lambda_{3}-0.1 \\
\text { set } \lambda_{1}=\lambda_{1}-0.1
\end{array}
\end{aligned}
$$

Table 1 displays likelihood values (in descending order) and corresponding weights $\left(\lambda_{1}, \lambda_{2}, \lambda_{3}\right)$ used to express $W$. Note that some intermediate

\footnotetext{
${ }^{5}$ We explore sensitivity to the weight matrix later, but see Lesage and Pace (2010) for a discussion of how perturbations in the spatial weight matrix impact estimates and inferences.
} 
results are omitted to save space. The table reveals that the best model fit is obtained when $W$ is built by assigning a weight of 0.6 to the matrix of distant collaboration partners $\left(W_{3}\right)$, a weight of 0.3 to the matrix of spatially proximate collaboration partners $\left(W_{2}\right)$, and a weight of 0.1 to the matrix of spatially proximate regions that are not FP collaborations $\left(W_{1}\right)$. Whereas, the case when $\mathrm{W}$ is expressed only by $W_{3}$ yields the worst fit.

Table 1: Log-Likelihood for Different Compositions of W

\begin{tabular}{ccccc}
\hline rank & $\lambda_{1}$ & $\lambda_{2}$ & $\lambda_{3}$ & log-likelihood \\
\hline 1 & 0.1 & 0.3 & 0.6 & -761.578 \\
2 & 0.0 & 0.3 & 0.7 & -761.617 \\
3 & 0.1 & 0.2 & 0.7 & -761.664 \\
4 & 0.0 & 0.2 & 0.8 & -761.818 \\
5 & 0.0 & 0.4 & 0.6 & -762.103 \\
6 & 0.1 & 0.4 & 0.5 & -762.164 \\
7 & 0.2 & 0.3 & 0.5 & -762.752 \\
8 & 0.0 & 0.5 & 0.5 & -762.806 \\
9 & 0.1 & 0.5 & 0.4 & -762.934 \\
10 & 0.2 & 0.2 & 0.6 & -762.951 \\
35 & 0 & 1 & 0 & -765.587 \\
39 & 1 & 0 & 0 & -765.898 \\
66 & 0 & 0 & 1 & -770.702 \\
\hline
\end{tabular}

This result indicate that a connectivity structure based on the notion of distance acting to spatially constrain knowledge flows distance is insufficient to explain observed variation in the way that interaction occurs among regional innovation processes. A connectivity structure that emphasizes FP collaborative network links as the primary ties between regions produces a better fit to observed variation in regional innovation, consistent with a view that knowledge flows are mediated by these ties. Further, it appears that the FP network among distant regions matters considerably for patenting in ICT. This suggests that regions benefit not only from knowledge produced in close vicinity but also from other parts of the world when deliberative links such as those reflected by FP networks are present. In other words, global knowledge flows are in play in addition to local knowledge flows.

In the context of our model specification, local knowledge flows comprise flows from two types of spatially proximate regions. The first type consists of spatial neighbors that are not collaboration partners $\left(W_{1}\right)$, and the second represent spatial neighbors that are also collaboration partners in FP programs $\left(W_{2}\right)$. Distinguishing $W_{2}$ from $W_{1}$ enables us to see that within the geographical neighborhood, interaction between neighbors that are reinforced by means of FP networks have a greater importance as an external knowledge source. This approach enables us to open-up the so called "black-box of local knowledge externalities" (Autant-Bernard et al., 2007b). Significant knowledge spillovers found in previous studies could reflect not 
simply pure knowledge externalities, but also strategic knowledge flows of the type considered here. It should be noted that even our approach leaves open the question of whether $W_{1}$ reflects pure knowledge externalities, since a spatially proximate region may not be a partner in $\mathrm{FP}$ projects, but some other type of knowledge network might be facilitating knowledge flows.

While comparing the weights of $\left(W_{1}\right)$ and $\left(W_{2}\right)$ enables us to scrutinize local knowledge flows, comparison of the weights of $\left(W_{2}\right)$ and $\left(W_{3}\right)$ allows us to further study network-mediated knowledge flows. Since the estimated weight associated with $W_{3}$ is larger than that for $W_{2}$, we infer that the effect of research inputs in the typical region have a stronger spillover effect on regional innovation performance in distant regions where collaboration links exist, than in proximate regions with collaboration partners.

Broekel (2012) using a different sample and methodology suggests that regression-based estimates and inferences that focus on the average or typical region may not be value for individual regions. He adopts a non-parametric approach to study the relationship between collaboration intensity and the efficiency at which innovation inputs in 270 German regions are related to innovation outputs in the electronics industry. He concludes that this relationship takes the form of an inverted-U shape. Regions with extremely high or low and unbalanced regional and inter-regional collaboration intensities tend to be innovation inefficient. Hence, our finding that the estimated weight for $W_{3}$ is greater than that for $W_{2}$ would not imply that a viable regional strategy to increase innovation performance would be to stop collaborating locally and focus only on distant collaborations.

The specification based on simultaneous use of $\left(W_{1}\right),\left(W_{2}\right)$ and $\left(W_{3}\right)$ sheds light on conclusions from the first empirical studies using R\&D collaborations to express the weight matrix (Maggioni et al., 2007, Ponds et al., 2010). Maggioni et al. (2007) used two weight matrices, one based on spatial proximity and the other on research collaborations. They compare specifications based on only a single type of weight matrix but find evidence of a positive impact of external knowledge on regional innovation performance. However, they find larger external knowledge flows when the weight matrix is defined on the basis of geographical proximity. Ponds et al. (2010), introduce both weight matrices in a single model specification and conclude that knowledge flows from both geographical neighbors as well as collaboration partners are important for innovation. This study, confirms that knowledge flows from collaboration partners matter for innovation. Our decomposition of the weight matrices into three components validates that these effects not only arise from local collaborations, but distant collaborations matter (indeed greatly) as well.

Having presented and interpreted our results, we need to discuss robustness to changes in the way we define $\left(W_{1}\right),\left(W_{2}\right)$ and $\left(W_{3}\right)$. As explained earlier in section 4.2, spatial proximity is defined as 12 nearest neighbors, and the collaboration network is built using FP collaborations in 2000. We 
experimented also using 10 nearest neighbors, and FP collaborations in 2003 and found out that the estimated weights for $\left(W_{1}\right),\left(W_{2}\right)$ and $\left(W_{3}\right)$ remain more or less the same, hence we do not report them here.

In Table 2 and Table 3, however, we report the coefficient estimates and the direct, indirect, and total effects estimates. Direct effects refer to the impact of a unit change in one of the research inputs in the typical region (say $i$ ) on the dependent variable Patents in the typical region $i$. In the context of our spatial Durbin model specification, this impact is slightly different from the maximum likelihood estimate $\boldsymbol{\beta}$ in (3), because an endogenous interaction model such as the SDM produces a small feedback effect.6

Indirect effects measure changes in patenting in other regions $j \neq i$ that arise from changes in region $i$ inputs, typically labeled spillovers. Since these are formally defined as cross-partial derivatives, $\partial y_{j} / \partial x_{i}$, we can also view indirect effects as reflecting $\partial y_{i} / \partial x_{j}$. These cross-partial derivatives can be expressed as off-diagonal elements of an $n \times n$ matrix, since changes in one region $(i)$ inputs can (potentially) impact all other $(n-1)$ regions as these effects work their way through the $n$-region network. The matrix of partial derivatives records these responses to the change in a single region $(i)$ input as an $n-1 \times 1$ vector, where $n$ is the number of regions. As is typical of regression coefficient estimates, we average over changes in all regions, $i=1, \ldots, n$, producing $n$ columns of $n-1 \times 1$ vectors of responses, or off-diagonal elements of an $n \times n$ matrix.

We report scalar summary measures for the direct and indirect effects in Table 3 set forth in Lesage and Pace (2009). Direct effect scalar summaries are based on an average of the $n$ different own-partial derivatives: $\partial y_{i} / \partial x_{i}, i=1, \ldots, n$, whereas indirect effect scalar summaries are calculated as the cumulative sum of off-diagonal elements in each row of the $n \times n$ matrix, which are then averaged to produce a scalar. The indirect effects in our specification capture spillovers arising from spatial proximity as well as collaborative networks.

Table 3 shows that a one percent change in the typical region $(i)$ investment in R\&D increases patents in region $i$ by 0.113 , which is an elasticity response because of the log-transformation. This direct effect differs slightly from the coefficient of 0.111 reported in Table 2, reflecting a small feedback effect. The indirect effect of this one percent change in region $i$ financial inputs to innovation would produce a spillover impact of 0.420 percent $\mathrm{cu}$ mulated over all spatial neighbors and network collaboration neighbors.7

\footnotetext{
${ }^{6}$ Feedback arises because changes in region $i$ inputs result in region $i$ output changes, and spillover impacts on output of neighboring regions, say $j$. These impacts on neighbors' output in turn produce spillover impacts on output of regions neighboring $j$, and region $i$ is one such neighboring region. (See Lesage and Pace (2009) for details).

${ }^{7}$ The importance of knowing that reported indirect effects represent spillovers cumulated over all other observations is that this explains why the spillover effects are larger than the direct effects. For a single neighboring region, the magnitude of spillover effects
} 
One could also view the indirect effect as showing the elasticity response of region $i$ patenting to a one percent change in financial inputs in all other regions. Lesage and Pace (2010) note that one can interpret indirect effects as showing how changes from inputs in all other regions $j$ spillover to impact region $i$, or we can interpret these as showing how changes to region $i$ inputs spillover to effect all other regions. In discussing the estimation results we adopt the latter approach, focusing on how changes in inputs in the typical region $i$ spillover to impact innovation activity in other regions $j$.

Table 2: Estimation Results

\begin{tabular}{lrr}
\hline Variable & Coefficient & z-probability \\
\hline BERD & 0.111 & 0.000 \\
HRST & 0.247 & 0.146 \\
Specialization & 0.017 & 0.609 \\
W*BERD & 0.485 & 0.000 \\
W*HRST $^{*}$ Hecialization & -0.890 & 0.044 \\
W*Spen $^{*}$ Patent & -0.811 & 0.016 \\
\hline
\end{tabular}

Table 3: Average Marginal Effects

\begin{tabular}{llll}
\hline Variable & Direct Effects & Indirect Effects & Total Effects \\
\hline BERD & $0.113^{* * *}$ & $0.420^{* * *}$ & $0.533^{* * *}$ \\
HRST & 0.242 & $-0.769^{* * *}$ & -0.526 \\
Specialization & 0.017 & $-0.708^{* * *}$ & $0-0.692^{* * *}$ \\
\hline$* * *$ & &
\end{tabular}

*** $99 \%$ confidence level

The results reveal no statistically significant direct effects associated with changes in the science and technology human resources input on the regional innovation process. This might be due to the fact that our measure for this variable does not reflect ICT specific human capital, but rather a measure persons educated and/or occupied in a science and technology related field 8 The indirect/spillover effects associated with changes in the quantity of science and technology human resources (HRST) of region $i$ on other regions are negative and significant. It seems plausible that increases in HRST in region $i$ would make this region attract (from neighbors and collaborators) science and technology professionals, because these people favor the large pool of expertise, opportunities for career development and the prestige of larger research bodies. Negative spillover impacts have generally been interpreted as reflecting competitive effects in the spatial econometrics literature, (Elhorst and Fréret, 2009).

would of course be much smaller than the reported cumulative impact of 0.420 .

${ }^{8}$ At NUTS-2 level, indicators on science and technology human resources are not available at the sectoral level. 
The direct effects for specialization are also not significant 9 Spillover or indirect effects are negative and significant, suggesting that a more specialized region $i$ may be able to recognize novelty and usefulness of new knowledge earlier than spatial and collaborative neighbors, and turn these new ideas into inventions and patents. Again, the negative spillover is consistent with a competitive effect between a more specialized region and its neighbors, so that higher levels of specialization in the typical region lead to lower innovation in neighbors and collaborators. Our model is static in nature, but there may be a dynamic aspect at work if regions that are already highly specialized tend to attract more resources in ICT, which could have a detrimental impact on innovation in surrounding regions.

\section{Conclusion}

We empirically examined the effects of external knowledge on a region's inventive activity by taking into account that regional innovation processes interact both locally and through knowledge networks. These networks enable both proximate and distant regions to learn from each other. Our methodology involved expressing connectivity between regions as a convex combination of three weight matrix structures. The first one reflects connections between spatially proximate regions that are not collaboration partners, the second identifies spatially proximate regions that are collaboration partners, and the third one reflects links to distant collaboration partners. Following theoretical reasoning set forth in Autant-Bernard and LeSage (2011) we used a spatial Durbin model specification to investigate patenting activity in the ICT field in 213 European regions over the period 2003-2009. Maximum likelihood estimates of scalar weights assigned to the three types of regional connectivity were used to draw inferences regarding the relative important of spatial proximity versus broader international connections based on deliberative collaboration arrangements.

The estimation results suggest that knowledge flows mediated by FP collaborations, especially among distant European regions, play an important role in explaining regional patenting activity in the ICT field. Our findings also indicate that a typical region $i$ benefits more from spillovers involving spatially proximate neighbors if there is a higher amount of interaction with these neighbors by means FP collaborations.

From a policy perspective, these findings support the rationale behind public policies that promotes creation of trans-national knowledge networks.

\footnotetext{
${ }^{9}$ We made use of Belsley, Kuh, Welsch variance-decomposition (Belsley et al. 1980) to check whether statistical insignificance of direct effects of HRST and specialization results from a multicollinearity problem. For condition index $=37$, variance decomposition factors for $\mathrm{W}^{*} \mathrm{BERD}$ and $\mathrm{W}^{*} \mathrm{HRST}$ are greater than 0.5 indicating a possible problem of dependence but no drastic changes are observed in coefficients when HRST is omitted from the model.
} 
From a theoretical point of view, the study provides some empirical results on the impact of spatial diffusion of knowledge on regional innovation performance. The study also attempts to overcome a major fallacy in modeling and interpretation that has received a great deal of criticism in earlier work (Breschi and Lissoni, 2001; Autant-Bernard et al., 2007b). The fallacy arises because local knowledge flows are frequently interpreted as the equivalent of local knowledge externalities. This interpretation emphasizes the tacitness of knowledge and spatial constraints on diffusion of tacit knowledge, while neglecting the role of strategic interactions. Our approach involved classifying proximate regions into both collaboration and non-collaboration partners, allowing us to shed additional light on the content of local knowledge flows, while not assuming that local flows are merely spatial externalities. From a methodological point of view, this study illustrates how the pattern of social or socio-economic interactions might be useful in describing the structure of dependence in certain spatial stochastic processes.

Although the study puts special emphasis on two main channels of knowledge diffusion, namely physical and social distance, the methodology we introduce could be applied to explore other channels. This would however require a national perspective, since a lack of regional data (on trade and labor mobility) prevent observation of these alternative possible channels at the regional level.

Finally, this study might be extended in at least two directions. First, the lack of regional data on innovation inputs in ICT represents an important limitation faced here. Using available data, three very broad measures of inputs were constructed, but more detailed data on R\&D inputs would enable better understanding of specifics of inter-regional interactions. Second, information covering a longer time period would allow a dynamic modeling approach that seems essential if we are to distinguish between dynamic and static knowledge flows.

\section{References}

Acharya, R. C. and W. Keller (2009), "Technology transfer through imports." Canadian Journal of Economics, 42, 1411-1448.

Agrawal, A., D. Kapur, and J. McHale (2008), "How do spatial and social poximity influence knowledge flows." Journal of Urban Economics, 64, $258-269$.

Almeida, Paul and Bruce Kogut (1999), "Localization of knowledge and the mobility of engineers in regional networks." Management Science, 45, 905-917.

Anderson, J E and E van Wincoop (2004), "Trade costs." Journal of Economic Literature, 42, 691-751. 
Anselin, L, A Varga, and Z Acs (1997), "Local geographic spillovers between university research and high technology innovations." Journal of Urban Economics, 42, 422-448.

Asheim, B, L Coenen, and J Vang-Lauridsen (2007), "Face-to-face, buzz and knowledge bases: Socio-spatial implications for learning, innovation and innovation policy." Environment and Planning C, 25, 655-670.

Autant-Bernard, C, P Billand, D Frachisse, and N Massard (2007a), "Social distance versus spatial distance in $R \& D$ cooperation: Empirical evidence from european collaboration choices in micro and nanotechnologies." $P a$ pers in Regional Science, 86, 495-519.

Autant-Bernard, C, J Mairesse, and N Massard (2007b), "Spatial knowledge diffusion through collaborative networks." Papers in Regional Science, 86.

Autant-Bernard, Corinne (2001), "Science and knowledge flows Evidence from the french case." Research Policy, 30, 1069-1078.

Autant-Bernard, Corinne and James LeSage (2011), "Quantifying knowledge spillovers using spatial econometric models." Journal of regional Science, 51, 471-496.

Balconi, Margherita, Stefano Breschi, and Francesco Lissoni (2004), "Network of inventors and the role of academia an exploration of italian patent data." Research Policy, 33, 127-145.

Baldwin, R and R Forslid (2000), "The core-Periphery model and endogenous growth: Stabilizing and de-stablizing integration." Economica, 67, 307-324.

Baldwin, R, P Matin, and G Ottaviano (2001), "Global economic divergence, trade and industrialisation: The geography of growth takeoffs." Journal of Economic Growth, 6, 5-37.

Beaudry, C and A Schiffauerova (2011), "Is canadian intellectual property leaving canada? a study of nanotechnology patenting." The Journal of Technology Transfer, 36, 665-679.

Bell, G G and A Zaheer (2007), "Geography, networks and knowledge flow." Organization Science, 18, 995-972.

Belsley, D A, E Kuh, and R E Welsch (1980), Regression Diagnostics: Identifying Influential Data and Sources of Collinearity. John Wiley \& sons, New York.

Boschma, R (2005), "Proximity and innovation: A critical assessment." Regional Studies, 39, 61-74. 
Boschma, R and A J Ter Wal (2007), "Knowledge networks and innovative performance in an industrial district: the case of a footwear district in the south italy." Industry an Innovation, 14.

Bottazzi, L and G Peri (2003), "Innovation and spillovers in regions: Evidence from european patent data." European Economic Review, 47, 687710.

Breschi, S and C Lenzi (2014), "The role of external linkages and gatekeepers for the renewal and expansion of u.s. cities' knowledge base, 1990-2004." Papers in Evolutionary Economic Geography.

Breschi, S and F Lissoni (2001), "Localized knowledge spillovers vs. innovative milieux: Knowledge tacitness reconsidered." Papers in Regional Science, 80, 255-273.

Breschi, S and F Lissoni (2009), "Mobility of inventors and networks of collaboration: An anatomy of localised knowledge flows." Journal of Economic Geography, 9, 439-468.

Broekel, Tom (2012), "Collaboration intensity and regional innovation efficiency in germany - a conditional efficiency approach." Industry and Innovation, 19, 155-179.

Cassiman, Bruno and Reinhilde Veugelers (2006), "In search of complementarity in innovation strategy: Internal $\mathrm{R} \& \mathrm{D}$ and external knowledge acquisition." Management Science, 52, 68-82.

Chesbrough, H (2003), Open Innovation: The New Imperative for Creating and Profiting from Technology. Harvard Business School Press, Boston.

Coe, D. T. and E. Helpman (1995), "International R\&D spillovers." European Economic Review, 39, 859-887.

Cowan, R and N Jonard (2004), "Network structure and the diffusion of knowledge." Journal of Economic Dynamics and Control, 28, 1557-1575.

Elhorst, J.P. (2010), "Spatial econometrics: Raising the bar." Spatial Economic Analysis, 5, 9-28.

Elhorst, J.P. and S. Fréret (2009), "Evidence of political yardstick competition in france using a two-regime spatial durbin model with fixed effects." Journal of Regional Science, 49, 931-951.

Gertler, M S and Y M Levitte (2005), "Local nodes in global networks: the geography of knowledge flows in biotechnology innovation." Working paper, Cornell University, School of Industrial and Labor Relations, URL http://digitalcommons.ilr.cornell.edu/articles/122. 
Glaeser, E., H. Kallal, J. Scheinkman, and A. Shleifer (1992), "Growth in cities." Journal of Political Economy, 100, 1126-1152.

Greunz, L. (2003), "Geographically and technologically mediated knowledge spillovers between european regions." The Annals of Regional Science, 37, 657-680.

Griliches, Z (1979), "Issues in assessing the contribution of research and development to productivity growth." The Bell Journal of Economics, $10,92-116$.

Griliches, Zvi (1990), "Patent statistics as economic indicators: A survey." Journal of Economic Literature, 28, 1661-1707.

Guiliani, E and M Bell (2005), "The micro-determinants of meso-level learning and innovation: evidence from a chilean wine cluster." Research Policy, 34, 47-68.

Hagedoorn, J (2002), "Inter-firm R\&D partnerships: an overview of major trends and patterns since 1960." Research Policy, 31, 477-492.

Hagedoorn, John and Ning Wang (2012), "Is there complementarity or substitutability between internal and external r\&d strategies?" Research Policy, 41, 1072-1083.

Hazır, C S and C Autant-Bernard (2014), "Determinants of cross-regional R\&D collaboration: Some empirical evidence from europe in biotechnology." The Annals of Regional Science, DOI: 10.1007/s00168-014-0606-4.

Henderson, Vernon (1997), "Externalities and industrial development." Journal of Urban Economics, 42, 449-470.

Hoekman, Jarno, Koen Frenken, and R.J.W. Tijsen (2010), "Research collaboration at a distance Changing patterns of scientific collaboration within europe." Research Policy, 39, 662-673.

Jaffe, B A, M Trajtenberg, and R Henderson (1993), "Geographic localization of knowledge spillovers as evidenced by patent citations." The Quarterly Journal of Economics, 108, 577-598.

Jensen, Morten Berg, Bjon Johnson, Edward Lorenz, and Bengt Ake Lundvall (2007), "Forms of knowledge and modes of innovation." Research Policy, 36, 680-693.

Kastelle, T and J Steen (2010), "Are small world networks always best for innovation?" Innovation: Management, Policy \& Practice, 12, 75-87. 
Keller, W. (1998), "Are international R\&D spillovers trade-related? analyzing spillovers among randomly matched trade partners." European Economic Review, 42, 1469-1481.

Kleinknecht, Alfred, Kees vanMontfort, and Eik Brouwer (2002), "The nontrivial choice between innovation indicators." Economics of Innovation and New Technology, 11, 109-121.

Lesage, James P. and R. Kelley Pace (2009), Introduction to spatial econometrics. CRC press.

Lesage, James P. and R. Kelley Pace (2010), "The biggest myth in spatial econometrics." Working Paper ssrn.1725503, Social Science Research Network.

Maggioni, M A, M Nosvelli, and T E Uberti (2007), "Space vs. networks in the geography of innovation: A european analysis." Papers in Regional Science, 86, 471-493.

Moreno, R., R. Paci, and S. Usai (2005), "Spatial spillovers and innovation activity in European regions." Environment and Planning A, 37, 17931812 .

Paier, M and T Scherngell (2008), "Determinants of collaboration in european R\&D networks Empirical evidence fom a binary choice model perspective." Available at SSRN: http://ssrn.com/abstract=1120081.

Peri, Giovanni (2005), "Determinants of knowledge flows and their effect on innovation." The Review of Economics and Statistics, 87, 308-322.

Ponds, Roderik, Frank van Oort, and Koen Frenken (2010), "Innovation, spillovers, and university-industry collaboration: An extended knowledge production function approach." Journal of Economic Geography, 10, 231255.

Roediger-Schluga, T and M J Barber (2006), "The structure of R\&D collaboration networks in the european framework programmes." Technical Report 2006-036, United Nations University (UNU-MERIT).

Saviotti, P P (1998), "On the dynamics of appropriability, of tacit and of codified knowledge." Research Policy, 26, 843-856.

Scherngell, T. and R. Lata (2013), "Towards an integrated european research area? findings from eigenvector spatially filtered spatial interaction models using European Famework Programme data." Papers in Regional Science, 92, 555-577. 
Sebestyen, T. and A Varga (2013), "Research productivity and the quality of inter-regional knowledge networks." The Annals of Regional Science, $51,155-189$.

Singh, J. (2005), "Collaboration networks as determinants of knowledge diffusion patterns." Management Science, 51, 756-770.

Ter-Wal, A L J (2013), "The dynamics of the inventor network in german biotechnology: geographical proximity versus triadic closure." Journal of Economic Geography, forthcoming.

Wuchty, S, BF Jones, and B Uzzi (2007), "The increasing dominance of teams in production of knowledge." Science, 316, 1036-1039.

Zucker, Lynne, Michael Darby, and Jeff Armstrong (1994), "Intellectual capital and the fim: The technology of geographically localized knowledge spillovers." NBER Woking Paper Series. 